Special Issue on

Public Enterprise Performance Benchmarking

Public Enterprise

Volume 22, Issue 1, pp. 79-91, 2016

https://doi.org/pehyj.2016.2201.05

\title{
On Discerning the Implications of Operating and Financial Leverage Ratios on the Systematic Risk of Enterprises: Evidence from Sensex Firms in India
}

\author{
N. R. Parasuraman and Ullas Rao \\ Shri Dharmasthala Manjunatheshwara Institute for Management Development (SDMIMD), \\ Mysore, India
}

Received August 2015; Revised November 2015; Accepted February 2016

\begin{abstract}
With the proliferation of advancements surrounding the investment analysis, an area that has received only token attention from the practitioners and academicians pertains to the factors (beyond the market) implicating the systematic risk of securities. It is surprising that, even while there is an overwhelming consumption of the notion surrounding the critical role rendered by the security beta in bearing the corporate valuation process to fruition, there is almost an implied incongruity towards establishing the implications of fundamental business variables bearing an influence on the beta value of securities. The seminal studies conducted by Hamada (1972); Mandelker \& Rhee (1984); Huffman (1989); Duett, et al., (1996); Ryan (1997); Faff, et al., (2002); Bernardo, et al., (2007); Alaghi (2011); and Ozdagli (2012) have attempted to discern the implication of fundamental business variables represented by operating and financial leverage on the systematic risk of enterprises that bear as significant additions to the literature in this area. However, the paucity of such studies particularly in respect of the emerging markets like India, serves as a significant contributor towards deciphering the interrelationship between systematic risks and fundamental business variables of enterprises thereby enriching the existing expanse of literature. In this paper, we seek to re-examine the hypothesis surrounding the implications of the fundamental business variables: Operating Leverage (OL) and Financial Leverage (FL) on the enterprise-wide systematic risk represented by security beta. On identifying OL and FL independently, we found a statistically significant relationship that FL bears on security beta. However, when we considered the Combined Leverage (CL), we observed a statistically significant relationship with security beta. Our sample consists of all the firms forming part of India's benchmark capital market (SENSEX).
\end{abstract}

Keywords: Systematic risk, operating, financial, combined leverage, econometric approach, multiple regressions, BSE, SENSEX

Reference to this paper should be made as follows: Parasuraman, N. R. and Rao, U. (2016). On Discerning the Implications of Operating and Financial Leverage Ratios on the Systematic Risk of Enterprises: Evidence from Sensex Firms in India. Public Enterprise,22(1), 79-91.DOI: 10.21571/pehyj.2016.2201.05 


\section{Introduction}

Enormous emphasis has been laid upon the critical input concerning the beta value of security, which together with the risk-free rate and risk premium, has a bearing on the cost of equity. All cash flows almost ubiquitously employ the cost of equity as at least one of the components for determining the discount rate when arriving at the intrinsic value for a corporate firm. The origin of security beta is best traced to the seminal work carried out by William Sharpe, which eventually earned him a Nobel Prize for proposing a highly influential work in the form of capital market hypothesis. The idea was conceived by Sharpe (1964) and later expanded by Solink (1974), Ross (1976), and Merton (1987).

Security beta, also known as the systematic risk in its simplest form, represents the sensitivity of security's return with that of the market. It is computed as the coefficient of the independent variable represented by the market's return when regressed over the security returns represented as a dependent variable. Alternatively, beta may also be computed using the covariance approach.

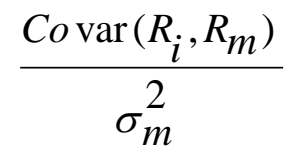

where:

$\beta=$ Beta of security $i$ in relation with market,

Covar $=$ Covariance between security returns $\left(\mathrm{R}_{\mathrm{i}}\right)$ and the market returns $\left(\mathrm{R}_{\mathrm{m}}\right)$,

$\sigma^{2}=$ Variance of market returns.

With beta of a market always given as 1 , the value of beta reflected by a firm determines the magnitude of systematic risk. For instance, a firm with a security beta of 1.5 is expected to have sensitivity to the tune of $150 \%$ making investment in the firm, a highly risky proposition. In contrast, a firm with a beta value of 0.2 is perceived as having a lower systematic risk. As an example, the firms representing the manufacturing and health-care sectors normally report high and low values of beta, respectively.

Taking the case of a plain-vanilla dividend discount model (DDM) as applied to a stable-firm, the influence rendered by security beta may be gauged from the equation delineated below.

$$
\mathrm{P}_{0}=\left(\frac{\mathrm{D}_{1}}{\mathrm{~K}_{\mathrm{e}}-\mathrm{g}_{\mathrm{n}}}\right)
$$

where:

$$
\mathrm{K}_{\mathrm{e}}=\mathrm{R}_{\mathrm{f}}+\left[\left(\mathrm{R}_{\mathrm{m}}-\mathrm{R}_{\mathrm{f}}\right) \beta_{\mathrm{i}}\right]
$$

As is evident from the above equation, the value assigned to the beta of a security has a direct bearing on the computed intrinsic value of a firm. It is worth mentioning that the value assigned to the beta while determining the discount rate at the terminal stage renders a significant role in influencing the corporate value of a firm. Financial theorists would argue that, with the ageing process of the firm accelerating at an increasing rate, it would be prudent to allow the beta of the firm at the terminal stage to converge with the market beta. Analysts building their "black- 
box" models would invariably factor this value with perhaps scant regard to the factors played out by fundamental business variables in influencing the terminal beta value. The last point needs some more elaboration. Here, we defined fundamental business variables as represented by the two ratios: OL and FL. Postponing the discussion in respect of OL for a later section, corporate finance has clearly established an inextricable influence of FL in determining the beta value. This may be appreciated by glancing at the mathematical equation represented below (Damodaran, 2006).

$\beta_{\mathrm{L}}=\beta_{\mathrm{U}}\left[1+(1-\mathrm{t})\left(\frac{\mathrm{D}}{\mathrm{E}}\right)\right]$

where:

$\beta_{\mathrm{L}}=$ Levered beta of a security,

$\beta_{\mathrm{U}}=$ Unlevered beta of a security,

$\mathrm{t}=$ corporate tax rate.

$\left(\frac{\mathrm{D}}{\mathrm{E}}\right)=$ Debt-to-Equity ratio

It is easy to gauge from the above equation that FL represented by $\left(\frac{D}{E}\right)$ will have the direct implication of increasing the beta value. The significance rendered by leverage in influencing the beta value is worth examining. Even while the norm among the early-stage or growing firms is invariably centered upon embracing an equitydominated capital structure - as the firms mature - and with every additional penny of equity for capital expansion coming with "strings attached", corporations find it much easier to opt for debt capital. The tax advantage apart, debt capital also serves the interests of management by preventing further dilution of control. However, an environment dominated by slowing or stagnant earnings in the wake of heightened competition among the industry players tends to exert significant pressure on the cash flows towards achieving the objective of debt-servicing. With free cash flows coming under pressure, the risk-propensity of the equity shareholders tends to rise, which is eventually reflected in an increased systematic risk led by higher beta value.

A pertinent issue to be pondered from the above discussion relates to the heightened influence of leverage or financial risks over business risks. In fact, corporate India in recent times has witnessed limited number of firms being nudged almost into extinction not due to enhanced business risks, but more owing to a flawed capital structure by embracing disproportionately high debt capital ${ }^{1}$.

Unlike the mathematical expression rendered by FL in influencing the beta value, unfortunately, there is no mathematical expression to decipher the linkage OL bears on the beta value. At best, the influence of OL may be represented by building an econometric model based on multiple regressions approach. The model and the

${ }^{1}$ As an example, Suzlon, India's leading manufacturer of wind-turbines, went through a very tumultuous phase primarily driven by its debt woes. While Suzlon managed to embrace a sound business model, yet the firm driven by its insatiable desire to purse international growth went for acquisitions supported by borrowed funds. With most of the acquisitions failing to yield the desired synergy, Suzlon had to ultimately witness a default on account of Foreign Currency Convertible Bonds (FCCBs) resulting in an instantaneous erosion of shareholders' wealth. 
subsequent treatment are dealt elaborately in the subsequent section. At this stage, there are some more pertinent points in respect of OL that deserve greater attention.

Corporate financial theory posits an inverse relationship between the discount rate $\left(\mathrm{K}_{\mathrm{e}}\right.$ or WACC, as the case may be) and the value of the firm, implying a higher discount rate that would lower the intrinsic value and vice versa. It is interesting to observe the plausible implications of assigning a theoretical beta value of " 1 " for a corporate enterprise that chooses to be an all-equity firm right until "eternity". In this case, the convergence of the existing lower or higher beta value to 1 gradually would be best explained by the application of business risk, as measured by OL. This is particularly true as decisions pertaining to capital structure (whether to lever the balance sheet) are best taken by the management of corporations. Zero-debt companies, therefore, have an implied obligation to generate higher returns as investors are inherently exposed to a greater degree of operating risks.

In the Indian context, in a study conducted by ET Intelligence, 52 corporations among Bombay Stock Exchange (BSE) 500 were found to be totally debt-free in the three years to 2014-15. Of the 52 corporations, 17 firms reported a double-digit three-year compounded annual growth rate (CAGR) in sales and net profits (ET Intelligence, 2015).

\section{Objectives and Scope of the Study}

In this paper, our primary objective is to discern the influence of business risk and financial risk on the systematic risk of a firm. In order to achieve the aforesaid objective, we developed a multiple regression model isolating extraneous variables bearing an influence on beta by relying upon financial measures represented by operating leverage (business risk) and financial leverage ratios operating as explanatory variables to capture the influence on systematic risk of a firm.

An implied rationale following the above is that business and financial risks surrounding a firm render a pre-eminent role in influencing the beta of a security. As ultimately, it is the systematic factors that lend an influence on a crosssection of securities as against unsystematic factors - as they are essentially diversifiable and therefore insignificant - our research endeavor rests upon providing an empirical support to the view delineated above.

\section{Theoretical Postulates Surrounding Implications of the Beta on Corporate Valuation, Particularly at the Terminal Stage}

It is interesting to observe the ramifications of the assigned beta value at the terminal stage. As stated above, analysts would prefer to assign a beta value of 1 (usually a range of 0.8 to 1.2) implying that the security risk will converge with the market risk with the gradual decline in the competitive advantages and the growth rates settling to a stable rate at the terminal stage. There are two preeminent factors bearing a significant impression on the assigned beta value, in particular, at the terminal stage.

\section{Financial Leverage}

With the maturing process of the firm setting in, corporate financial theory would posit that mature firms would find it much harder to raise additional layers of capital by equity than by debt. The argument towards this postulate flows from the fact that investment in a maturing firm (with its waning influence in dictating the industry and customers) would be deemed as much riskier and consequently less profitable by equity investors as against a young firm that holds out plenty of promising opportunities at least for investors like venture capitalists, private equity, and angel investors, who are cuddled with the prospects of earning an attractive IRR on their initial investment. 
With such a possibility, it is fair to expect the capital structure to have some traces of debt for a firm at the maturity stage that chooses to retain its 'all-equity characteristic' all along the growth phase ${ }^{2}$. With leverage coming into fruition, ceteris paribus, the beta value is influenced by the degree of financial leverage as given in Equation 1. That is, for an all-equity firm, the transition takes place from a previously unlevered beta value to a levered beta value.

\section{Operating Leverage}

Yet another significant aspect of a firm's business bearing an influence on the beta value pertains to the operating leverage. Operating leverage represents the business risk measured by the volatility in earnings and is influenced by the ability of a firm to derive the benefits of the "economies of scale" by virtue of the presence of "fixed costs." Consider again a firm that gradually matures over its life-cycle with the prospects of diminishing the economies of scale due to the limitations imposed on the productive capacity of the firm. In such a scenario, the volatility in earnings as a consequent impact of enhanced business risk is expected to have a discernible influence on the beta value. It is not unreasonable to expect firms (which are virtually debt-free) to witness an increased equity risk primarily owing to an upward revision of its beta value. A more pertinent issue would relate to the underlying mechanism towards capturing the impact of the operating leverage on the beta value of a firm.

There is one significant caution that must be exercised by researchers when working with operating leverage. In his paper on operating leverage, Novy-Marx (2010) made the following observation. "A more sophisticated analysis must recognize that higher operating costs may influence firms to reduce productions sooner in the face of falling demand, resulting in higher cost betas for highly geared firms. Moreover, the true level of gearing, which depends on capitalized value of all future costs and revenues, is not truly observable. While market values provide a good proxy for the difference in the capitalized values of costs and revenues, it is difficult to find good proxies for these individually. Cross-industry differences in accounting practices, and the prevalence of leases, add further noise to accounting variables that might conceivably be related to the operating leverage".

An interesting corollary flowing from the above discussions pertain to the degrees of influence borne by operating and financial leverage on the systematic risk as measured by the beta value. With the lens of investors consistently placed on the management of a firm, corporate executives have an implied responsibility towards continuously enhancing the shareholders' wealth as measured by the intrinsic value on per-share basis. Given that there is an inverse relationship between the intrinsic value of a firm and its corresponding discounting rate, the influence permitted by beta of a security bears significance. That is a firm that does not wish to seek raise additional capital by debt must have the inherent responsibility to control business risks in order to keep the influence of operating leverage on the beta value under check. Otherwise, in the fall-out of increased business risks, the management will be pressured to assume financial leverage (with its soothing influence on WACC arising out of tax-shield) in order to maximize the intrinsic value.

The above delineated points clearly demonstrate the inexorable influence remitted by the fundamental business variables on the systematic risk of a firm.

${ }^{2}$ Schmid and Gomes (2010) in their study found that, in the presence of financial market imperfections, leverage and investments appear to be highly correlated so that highly levered firms are also mature firms with relative more (safe) book assets and fewer (risky) growth opportunities. 


\section{Literature Review}

A popular model that has witnessed a heightened degree of attention from the scholastic community relates to the one propagated by Hamada (1972). The model seeks to decipher the underlying relationship between systematic risk and the leverage ratios represented by OL and FL as depicted below.

$$
\beta=\beta^{*}+\beta^{*}(1-\tau)\left(\frac{D}{E}\right)
$$

The model served as a seminal contribution for spearheading research relating to the empirical examination of the relationship between the leverage ratios (operating and financial) and the systematic risk. The model was however criticized by Mandelker and Rhee (1984) who pointed out the following:

1. Equation does not explicitly introduce the degrees of two types of leverage in its expression.

2. The model suffers from various econometric problems caused by a nonlinear multiplicative effect of financial structure on operating risk as measured by $\beta^{*}$.

3. Equation assumes corporate debt is risk-free.

In their paper, Stone and Hill (1980) pointed towards the need for improved methods of estimating operating risk including its decomposition into more primitive components. They observed that both financial structure and systematic operating risks led a significant influence on market beta values. On the basis of this observation, they hold that forecasts of financial structure and operating risks are necessary towards accurately estimating beta values. They further found evidence to the effect that accounting betas do a better job towards capturing systematic risks as opposed to covariance-based measure.

In their own work, Mandelker and Rhee (1984) carried out a study with the objective to capture the underlying relationship between the systematic risk and the operating and financial leverage ratios. While their findings suggest that the degrees of operating leverage (DOL) and financial leverage (DFL) explain a large portion of the variation in beta; the inherent weakness reflected by the DOL, when used as an independent variable in the regression equation suggesting a smaller explanatory power, points out to the potential challenges posed in isolating DOL towards explaining the systematic risk. Besides, the observance of poor $\mathrm{R}^{2}$ further exacerbates the robustness of the proposed model.

The study conducted by Huffman (1989) pointed out to the typical deficiencies confronted while transforming the earnings variable into their logarithmic equivalents. A major source of irritation flows from the logarithmic transformation of firms with negative earnings. The study found a positive relationship between systematic risk and financial leverage, and a negative relationship between systematic risk and operating leverage. The study also did not find any support for the conjecture that there is a trade-off between operating leverage and financial leverage.

The study conducted by Duett, Merikas, and Tsiritakis (1996) sought to enhance the understanding of the linkage between product markets and financial markets. The study proposed formulation of demand beta that is described as an important source of uncertainty in a security's return. The introduction of demand elasticity serves as an alternative formulation of inherent risk to that delineated by Mandelker and Rhee (1984).

The study conducted by Ryan (1997) related to a survey of research with regard to accounting numbers to systematic equity risk. The study points out to the deficiencies arising out of employment of traditional accounting earnings numbers as reflected in historical financial statements to represent operating risk. It argues for employment 
of fair-value accounting and well considered disaggregation of balance sheet accounts and major accrual estimates. The study consequently points out to the blurring of the sources of risk as operating and financing and criticizes the limited focus accorded by the financial reports towards providing direction only in respect of information concerning financial leverage, often at the cost of operating risk.

The study conducted by Bernardo, Chowdhry, and Goyal (2007) related to the decomposition of a firm's beta into beta of assets-in-place and beta-of-growth opportunities. The study empirically observed the beta of growth opportunities to be greater than the beta of assets-in-place for virtually all the industries over all periods of time dating back to 1977. In this paper, the authors posit that growth beta firms have a greater bearing on the project's cost of capital. They opine that assuming a $6 \%$ equity risk premium accounting for growth has the potential to alter cost of capital by as much as $2 \%$ to $3 \%$.

Yet most studies pointed out to the significant relationship held by financial leverage towards explaining the systematic risk of firms. The evidence is found in notable studies including Faff, Brooks, and Kee (2002), Alaghi (2011) and more recently by Ozdagli (2012).

\section{Conceptual Framework Surrounding Operating and Financial Leverage}

Before proceeding with the presentation of the empirical model, it is useful to define the fundamental business variables, OL and FL, along with the depiction of the underlying computational procedures.

OL represents the business risk of a firm as measured by the volatility in earnings. Simply put, it may be defined as a ratio of percentage change in operating income ( $\Delta$ EBIT) over percentage change in sales ( $\Delta$ Sales). In other words, we say a proportionate change in operating income brought about by an incremental change in sales due to the presence of OL.

That is:

\section{$\Delta$ Sales x $\mathrm{OL}=\Delta \mathrm{EBIT}$}

Putting it differently,

$$
\mathrm{OL}=\left(\frac{\Delta \mathrm{EBIT}}{\Delta \text { Sales }}\right)
$$

Also, OL may be computed alternatively as a ratio of Contribution over Operating Profit (EBIT). That is:

$$
\mathrm{OL}=\left(\frac{\text { Contribution }}{\text { EBIT }}\right)
$$

where:

Contribution $=$ Sales - Variable Costs, EBIT $=$ Contribution - Fixed Costs.

FL is expressed as a ratio over percentage in earnings-after-taxes ( $\triangle \mathrm{EAT}$ ) over percentage change in operating income $(\triangle \mathrm{EBIT})$. In simple sense, FL represents the impact on earnings-after-taxes (EAT) owing to the presence of 
fixed costs in the form of interest expenses. Conventionally, an incremental change in EBIT leads to a more than proportionate change in EAT due to the influence of FL. That is:

$\mathrm{FL}=\left(\frac{\Delta \mathrm{EAT}}{\Delta \mathrm{EBIT}}\right)$

Also, it may be represented as a ratio of operating profit (EBIT) over pre-tax income (EBT).

That is:

$\mathrm{FL}=\left(\frac{\mathrm{EBIT}}{\mathrm{EBT}}\right)$

\section{The Empirical Model}

Our empirical model seeks to examine the null hypothesis surrounding no significant impact borne by the leverage ratios, OL and FL, on the systematic risk of firms as represented by their beta values. Consequently, we formulate a linear econometric model based on multiples regressions as depicted below.

$\beta_{\mathrm{i}}=\gamma_{1} \mathrm{OL}+\gamma_{2} \mathrm{FL}$

(Model I)

where:

$\beta_{\mathrm{i}}=$ Beta value of a firm,

$\gamma_{1}=$ Coefficient of OL,

$\gamma_{2}=$ Coefficient of FL.

The mutual interplay of the variables representing OL and FL leads to combined leverage (CL), which is computed as a product of OL and FL. Symbolically, it may be represented as:

$\mathrm{CL}=\mathrm{OL} \times \mathrm{FL}$

That is:

$$
\begin{aligned}
\mathrm{CL} & =\left(\frac{\Delta \mathrm{EBIT}}{\Delta \text { Sales }}\right) \times\left(\frac{\Delta \mathrm{EAT}}{\Delta \mathrm{EBIT}}\right) \\
& =\left(\frac{\Delta \mathrm{EAT}}{\Delta \text { Sales }}\right)
\end{aligned}
$$

By its derivation, CL seeks to capture the combined effect of OL and FL. Consequently, we derive a modified version of the model depicted above to capture the impact of CL on the systematic risk of firms as represented by their beta values.

$\beta_{\mathrm{i}}=\gamma_{1} \mathrm{CL}$

(Model II) 
where:

$\beta_{\mathrm{i}}=$ Beta value of a firm,

$\gamma_{1}=$ Coefficient of CL.

Our study endeavors to seminally contribute to the practitioner and the academia by proposing a robust model that seeks to explain the implications of corporate decisions surrounding operating and financial risk on the systematic risk of firms in India. As posited by corporate valuation theory, every firm seeks to maximize the corporate value by maximizing growth, cash flows, and minimizing (or at least controlling) the risks. Typical valuation models, including the popularly employed Discounted Cash-Flow (DCF) models, present varied frameworks enabling corporate managers to appreciate the mutual interconnectedness between the financial variables in determining the corporate value.

In keeping with the abovementioned objective, we selected a sample that is representative of growth firms as represented by their market capitalization and commanding a similar risk profile. Imposition of these parameters leads us to select all the firms constituting India's oldest and most tracked benchmark capital market index led by SENSEX. SENSEX represents a diversified portfolio of top 30 companies that are selected predominantly using the criteria of market capitalization. The performance of these blue-chip companies virtually represents the state-of-theeconomy.

Our initial sample included all the 30 firms. Given the unavailability of the most recent financial data in respect of one firm along with the observation of negatives values of OL and FL (as there is not much meaning attached for negative OL and FL values) for the other seven firms, the final sample consisted of 22 firms. The data in respect of beta values, operating income, and earnings-after-tax were retrieved as on March $31^{\text {st }}, 2015$. OL and FL values were computed using the Equation 2 and Equation 3 depicted earlier. The data including the beta values was retrieved from Capitaline databases.

\section{Empirical Results and Inferences}

The empirical results flowing from the above delineated models are discussed below.

Table 1

Regression Results Derived from Model I

\begin{tabular}{cc}
\hline & Regression Statistics \\
\hline $\mathrm{R}^{2}$ & 0.6609 \\
Standard error & 0.6203 \\
F-statistic & 17.5411 \\
\hline
\end{tabular}

Note. Source: Excel analysis.

Table 2

Regression Parameters Derived from Model I

\begin{tabular}{cccc}
\hline \multicolumn{2}{c}{ Dependent variable } & Statistical parameters & \multicolumn{2}{c}{ Regression coefficients } \\
\cline { 3 - 4 }$\beta_{\mathrm{i}}$ & & $\gamma_{1}$ & $\gamma_{2}$ \\
\cline { 3 - 4 } & Standard error & 0.0091 & 0.5236 \\
\hline
\end{tabular}




\begin{tabular}{crc} 
& & \\
t-value & 0.1846 & 4.0854 \\
p-value & 0.8556 & 0.0007 \\
Confidence Interval (lower) & -0.0946 & 0.2543 \\
Confidence Interval (upper) & 0.1128 & 0.7929 \\
\hline
\end{tabular}

Note. Source: Excel analysis.

Table 3

Regression Results Derived from Model II

\begin{tabular}{cc}
\hline & Regression Statistics \\
\hline $\mathrm{R}^{2}$ & 0.2327 \\
Standard error & 0.9082 \\
F-statistic & 5.7637 \\
\hline
\end{tabular}

Note. Source: Excel analysis.

Table 4

Regression Parameters Derived from Model II

\begin{tabular}{ccc}
\hline Dependent variable & Statistical parameters & Regression coefficients \\
\cline { 3 - 3 }$\beta_{\mathrm{i}}$ & Coefficient & $\gamma_{1}$ \\
\cline { 3 - 3 } & Standard error & 0.0516 \\
& t-value & 0.0215 \\
& p-value & 2.4007 \\
& Confidence Interval (lower) & 0.0268 \\
& Confidence Interval (upper) & 0.0066 \\
\hline
\end{tabular}

Note. Source: Excel analysis.

From the above results, we infer that while FL as a variable is statistically significant at $5 \%$ level of significance bearing a clear implication on the systematic risk of a firm, the results in respect of OL appear mixed. The observed results are consistent with those observed by Alaghi (2011) and Ozdagli (2012).

When the OL's impact is captured independently, we failed to observe an evidence of statistically significant impact; however, when observed along with FL in the form of CL, we observe a statistically significant relationship held by OL and FL together as in CL at 5\% level of significance thereby rejecting the null underlying no impact of OL and FL on the systematic risk of firms. The results are consistent with those observed by Huffman (1989).

The above results clearly show that the systematic risk, as reflected by the beta value, is better reflected by OL and FL together. This is cognizable from the fact that corporate managers seek to control both operating and financial risks at the same time implying an equal-weighted attention accorded by the top management led by its shareholders towards managing and mitigating these risks.

In recent times, we have witnessed the cases of Suzlon Ltd. and Wockhardt Ltd. that were once revered as darlings of the stock market exemplifying an excellent business model with virtually negligible operating risks. However, the quest of the management to expand their business drove these corporations to assume substantial amounts of debt exacerbating their levered position. In the following years, with the interest burden only expanding, the management at these firms faced the prospect of pushing their businesses to almost extinction. Lately though, these firms learned 
the lessons of the perils of excessive leverage and have subsequently taken measures to gradually offload debt by engaging in divestitures and other measures of corporate restructuring. The cash realized have been utilized for shelving debt from their balance sheet with a consequent favorable impact on the stock prices commanded by these firms (Balasubramanyam, 2013). These instances point to the significant influence commanded by capital structure on firms at least among the corporations in India.

Having posited the significance underlined by operating and financial risks together, it is ubiquitously accepted by both theoreticians and practitioners alike about the critical role rendered by financial leverage in influencing the equity risk of enterprises. After-all a few of the well-managed corporations with virtually negligible operating risks have been almost driven to "extinction" due to the unbridled desire of the management to assume higher debt in order to drive expansive capital investment proposals often at the detriment of the interests of the larger shareholders.

\section{Conclusions}

In this paper, whilst we seek to empirically examine the influence borne by the fundamental business variables towards explaining the systematic risks encountered by corporate firms, it will be worthwhile to extend the study by establishing the effects of systematic risk on the overall value of a corporate firm. Besides, there is always an enhanced scope for future researchers to extend this study by observing the above delineated research problem by looking at a larger sample as retrieved from other competitive growth indices available within the Indian capital markets.

In this paper, we seek to empirically examine the hypothesis surrounding the influence exerted by fundamental business variables on the systematic risk of the SENSEX constituent firms in India. We found a statistically significant evidence of the impact borne by FL in explaining the systematic risk. The implications of OL towards explaining the systematic risk are found only in conjunction with FL in the form of CL.

The fact that capital structure decisions still play an overwhelming large part in deciding the future corporate maneuvers at the board rooms is a testament to the large significance accorded to both management and mitigation of financial risks.

\section{References}

Alaghi, K. (2011). Financial leverage and systematic risk. African Journal of Business Management, 5(15), 66486650.

Balasubramanyam, K. R. (2013, January 29). Can Suzlon do a wockhardt?. Business Today. Retrieved from http://www.businesstoday.in/opinion/perspective/suzlon-wockhardt/story/191893.html

Bernardo, A. E., Chowdhry, B. \& Goyal, A., (2007). Growth options, beta, and the cost of capital. Financial Management, 36(2), 1-13. dx.doi.org/10.1111/j.1755-053X.2007.tb00084.x

Duett, E. H., Merikas, A., \& Tsiritakis, M. D. (1996). A pedagogical examination of the relationship between operating and financial leverage and systematic risk. Journal of Financial and Strategic Decisions, 9(3), 1-7.

ET Intelligence (2015). Why investors should consider zero debt companies like Infosys, GSK. India, Mumbai: The Economic Times.

Faff, R. W., Brooks, R. D. \& Kee, H. Y. (2002). New evidence on the impact of financial leverage on beta risk: A time-series approach. The North American Journal of Economics and Finance, 13(1), 1-20. dx.doi.org/10.1016/s1062-9408(02)00059-1 
Hamada, R. S. (1972). The effect of the firm's capital structure on the systematic risk of common stock. The Journal of Finance, 27(2), 435-452. dx.doi.org/10.1111/j.1540-6261.1972.tb00971.x

Huffman, S. P. (1989). The impact of the degrees of operating and financial leverage on the systematic risk of common stocks: Another look. Quarterly Journal of Business and Economics, 28(1), 83-100.

Mandelker, G. N., \& Rhee, S. G. (1984). The impact of the degrees of operating and financial leverage on systematic risk of common stocks. The Journal of Financial and Quantitative Analysis, 19(1), 45-57. dx.doi.org/10.2307/2331000

Merton, R. C. (1987). A simple model of capital market equilibrium with incomplete information. The Journal of Finance, 42(3), 483-510. dx.doi.org/10.2307/2328367

Novy-Marx, R. (2010). Operating leverage. Review of Finance, 15(1), 103-134. dx.doi.org/10.1093/rof/rfq019

Ozdagli, A. K. (2012). Financial leverage, corporate investment, and stock returns. The Review of Financial Studies, 25(4), 1033-1069. dx.doi.org/10.1093/rfs/hhr145

Ross, S. A. (1976). The arbitrage theory of capital asset pricing. Journal of Economic Theory, 13(3), 341-360. dx.doi.org/10.1016/0022-0531(76)90046-6

Ryan, S. G. (1997). A survey of research relating accounting numbers to systematic equity risk, with implications for risk disclosure policy and future research. Accounting Horizons, 11(2), 82-95.

Schmid, L. \& Gomes, J. F. (2010). Levered returns. The Journal of Finance, 65(2), 467-494. dx.doi.org/10.1111/j.1540-6261.2009.01541.x

Sharpe, W. F. (1964). Capital asset prices: A theory of market equilibrium under conditions of risk. The Journal of Finance, 19(3), 425-442. dx.doi.org/10.2307/2977928

Solink, B. H. (1974). An equilibrium model of the international capital market. Journal of Economic Theory, 8(4), 500-524. dx.doi.org/10.1016/0022-0531(74)90024-6

Stone, B. K., \& Hill, N. C. (1980). Accounting betas, systematic operating risk, and financial leverage: A riskcomposition approach to the determinants of systematic risk. Journal of Financial and Quantitative Analysis, 15(3), 595-637. dx.doi.org/10.2307/2330401

\section{Authors Note}

The authors would like to express their sincere gratitude towards the special issue editor and the reviewers for making very helpful suggestions at every stage leading to a substantial improvement in the paper.

Correspondence concerning this article should be addressed to U. Rao, Shri Dharmasthala Manjunatheshwara Institute for Management Development (SDMIMD), No-1 Chamundi Hill Road, Siddharthanagar, Mysore 570011, India. Email: ullasrao@sdmimd.ac.in

\section{Biographical Notes}

N. R. Parasuraman has 30 years of experience in diverse areas of finance. His special areas of teaching and research are Strategy, Financial Derivatives, and Multinational Finance. He is a visiting faculty at the Indian Institute of Management, Rohtak and Indian Institute of Management, Udaipur. He has published 30 papers and concept articles in various journals. He has also authored a book titled 'FINANCIAL MANAGEMENT - a Step by Step approach' which has been published by Cengage Learning. His earlier book 'FUNDAMENTALS OF FINANCIAL DERIVATIVES' published by Wiley India Limited, which is very popular among the teachers and students of derivatives, has gone into a third edition.

Ullas Rao earned his Doctorate in Commerce for the work on "Posterior Analysis of Mergers \& Acquisitions in International Financial Scenario during the Last Decade" from the University of Mysore, carried out under the 
guidance of Dr. M. R. Suryanarayana Murthy. His research makes significant theoretical and empirical contribution by proposing new approaches for capturing the impact of M\&A activity on the wealth status of shareholders. He has presented papers at leading International Conferences including the 22nd Australasian Conference on Banking \& Finance, held at Sydney, Australia, in 2009. His research work has been published in reputed national and international journals.

\section{Appendix}

\section{List of Sample Firms Constituting BSE SENSEX}

\begin{tabular}{cccc}
\hline & Scrip Code & Company & Sector \\
\hline 1 & 532215 & Axis Bank Ltd & Banking \\
2 & 500103 & Bharat Heavy Electricals Ltd & Heavy Industry \\
3 & 532454 & Bharti Airtel Ltd & Telecommunications \\
4 & 500124 & Dr. Reddy's Laboratories Ltd & Pharmaceuticals \\
5 & 532155 & Gail India Ltd & Oil \& Gas \\
6 & 500180 & HDFC Bank Ltd & Banking \\
7 & 500182 & Hero MotoCorp Ltd & Automobile \\
9 & 500696 & Hindustan Unilever Ltd & FMCG \\
10 & 500010 & Housing Development Finance Corp & Financial Institution \\
11 & 532174 & ICICI Bank Ltd & Banking \\
12 & 500209 & Infosys Ltd & IT Software \\
13 & 500875 & ITC Ltd & Diversified Conglomerate \\
14 & 500257 & Lupin Ltd & Pharmaceuticals \\
15 & 500520 & Mahindra \& Mahindra Ltd & Diversified Conglomerate \\
16 & 532500 & Maruti Suzuki India Ltd & Automobile \\
17 & 500312 & Oil \& Natural Gas Corp Ltd & Oil \& Gas \\
18 & 500112 & State Bank of India & Banking \\
19 & 532540 & Tata Consultancy Services Ltd & IT Software \\
21 & 500470 & Tata Steel Ltd & Steel \\
22 & 507685 & Wipro Ltd & IT Software \\
\hline
\end{tabular}

